\title{
Implementasi Metode Fuzzy Tsukamoto Dalam Memprediksi Jumlah Produksi TMG
}

\author{
Eki Juliana $^{1}$, Ragil Kurniawan ${ }^{2}$ \\ Fakultas Ilmu Komputer, Program Studi Sistem Informasi \\ Universitas Darwan Ali \\ Ekijuliana6@gmail.com
}

\begin{abstract}
Abstrak
Usaha kuliner adalah salah satu usaha yang banyak digemari dan diminati oleh masyarakat. Sejak dulu hingga sekarang, usaha kuliner seperti jajanan khas daerah terus berkembang tiada habisnya. Salah satu jajanan khas daerah yang berasal dari kota Sampit yaitu Telur Mata Gajah. Di kota Sampit sendiri salah satu usaha kuliner yang Sering di cari warga dan cukup dikenal yaitu Telor Mata Gajah Amrozy yang berlokasi di Jalan Yos Sudarso atau Kompleks Pujasera di Kota Sampit, persis bersebelahan dengan Taman Kota Sampit. Menjadi tempat jajanan yang dikenal dan ramai dikunjungi membuat pemilik usaha kesulitan dalam menentukan jumlah produksi yang mesti disiapkan dalam memenuhi jumlah permintaan dalam penjualan nya. Penelitian ini bertujuan untuk menyelesaikan permasalahan di atas dengan menggunakan sebuah metode. metode yang digunakan oleh penulis pada penelitian ini adalah metode fuzzy Tsukamoto. Dari hasil penelitian yang dilakukan oleh penulis diperoleh hasil yakni 2162 TMG yang harus diproduksi. Sehingga hasil penelitian ini bisa menjadi pertimbangan untuk menentukan jumlah rata rata dalam memproduksi TMG
\end{abstract}

Kata kunci: Produksi, Prediksi Produksi, Fuzzy Tuskamoto, Telur Mata Gajah.

The culinary business is one of the most popular companies and is in demand by the community. Since then until now, culinary companies such as local specialties have continued to grow endlessly. One of the typical regional snacks from the city of Sampit is Elephant Eye Eggs. In the town of Sampit itself, one of the culinary businesses that are often sought after by residents and are quite well known is Telor Mata Gajah Amrozy, which is located on Jalan Yos Sudarso or the Pujasera Complex in Sampit City, right next to Sampit City Park. Being a wellknown and visited place for snacks makes it difficult for business owners to determine the production required to meet the demand for sales. This study aims to solve the above problems by using a method. The method used by the author in this study is the Tsukamoto fuzzy method. From the author's research results, it was found that 2162 TMG had to be produced. So that the results of this study can be a consideration to determine the average amount in creating $T M G$

\section{Keywords: Production, Production Prediction, Fuzzy Tsukamoto, Elephant Eye Eggs.}

\section{PENDAHULUAN}

Usaha "Telor Mata Gajah Amrozy"

yang berlokasi di J1. Yos Sudarso, Kompleks Pujasera Taman Kota, Sampit,
Kalimantan Tengah, merupakan usaha yang bergerak di bidang kuliner jajanan Telur Mata Gajah dimana telur mata gajah adalah jajanan khas kota Sampit yang 
cukup populer di seluruh kalangan masyarakat, jajanan ini mencangkupi dari kalangan masyarakat bawah sampai dengan masyarakat atas, jajanan ini juga disukai oleh semua kalangan usia. Telur mata gajah adalah makanan yang tebuat dari perpaduan tepung terigu, sayur dan bumbu-bumbu yang digoreng dalam cetakan berbentuk bulat dengan telur puyuh yang diceplok saat proses penggorengan.

Dalam pembuatan telur mata gajah diperlukan perhitungan dan analisa yang baik sedangkan pada usaha Telor Mata Gajah Amrozi sendiri belum menggunakan metode dalam pengelolaan usahanya untuk perhitungan produksi telur mata gajah, terlepas dari hal tersebut perhitungan dan anilisa yang baik sangat diperlukan. Produksi yang baik adalah produksi yang mempunyai keuntungan maksimal yang dimana didapatkan dari penjualannya yang maksimal. Apabila produksi telur mata gajah lebih banyak dari jumlah permintaan pelanggan atau bahkan kurang dari permintaan pelanggan maka usaha akan mengalami kerugian. Usaha Telor Mata Gajah Amrozy sering kali terjadi seperti hal di atas karena ketidaktahun dalam menganalisa keinginan pelanggan, usaha Telor Mata Gajah Amrozy hanya menggunakan perkiraan dalam memproduksi telur mata gajah, Dilihat dari masalah tersebut perlu dilakukan suatu Analisa untuk menentukan keputusan dalam memproduksi jumlah telur mata gajah yang mesti disiapkan. Metode yang digunakan oleh penulis adalah dengan mengimplementasikan metode Fuzzy Tsukamoto dengan data yang diperoleh langsung oleh penulis dari pemilik usaha telor Mata Gajah Amrozy yaitu data persediaan dan data penjualan serta data produksi dalam satu minggu terakhir.

\section{Tujuan Penelitian}

Tujuan dari penelitian ini adalah untuk menentukan prediksi jumlah produksi yang sesuai dalam memenuhi permintaan pelanggan yang tidak menentu, yaitu dengan pengimplementasian metode Fuzzy tsukamoto dalam membuat perencanaan untuk memprediksi jumlah produksi yang diharapkan dapat meningkatkan keuntungan dimana produksi yang maksimal didapatkan dari suatu penjualan yang maksimal.

\section{Tinjauan Pustaka \\ Logika Fuzzy}

Menurut Sutojo et al Logika Fuzzy adalah metode sistem kontrol pemecahan suatu masalah yang cocok untuk diimplementasikan pada sistem sederhana, sistem kecil, sistem kontrol, jaringan komputer dan embedded system. Dalam logika klasik dinyatakan bahwa segala sesuatu bersifat biner, artinya sesuatu tersebut hanya memiliki dua kemungkinan, Ya atau Tidak, Benar atau Salah. Dua kemungkinan tersebut mempunyai nilai keanggotaan 0 atau 1. Suatu keadaan dapat memiliki dua nilai Ya dan Tidak, Benar dan Salah secara bersamaan, tetapi besar nilainya tergantung pada derajat keanggotaan yang dimilikinya. Logika Fuzzy dapat diimplementasikan pada banyak bidang, salah satunya adalah pada sistem diagnosis penyakit (Sutojo, et al., 2011).

\section{Operasi Himpunan Fuzyy}

Operasi himpunan fuzzy digunakan untuk proses inferensi atau penalaran. hasil dari operasi dua himpunan disebut alphapredikat. Operasi himpunan fuzzy memiliki tiga operator dasar yang sering digunakan untuk melakukan operasi himpunan fuzzy (Sutojo, et al., 2011). 
1. Operasi Gabungan (Union)

Operasi gabungan atau biasa disebut dengan operasi $O R$ dari himpunan fuzzy X dan Y dinyatakan sebagai X U Y. Operator $O R$ didapatkan dengan mengambil nilai $M A X$.

2. Operasi Irisan (Intersection)

Operasi irisan atau operasi $A N D$ dari himpunan fuzzy A dan $\mathrm{B}$ dinyatakan sebagai $\mathrm{X} \cap \mathrm{Y}$. operator $A N D$ diperoleh dengan mengambil nilai keanggotaan nilai $M I N$.

3. Operasi Komplemen (Complement)

Operasi komplemen atau operasi NOT didapatkan dengan mengurangkan nilai keanggotaan pada himpunan yang bersangkutan.

\section{Rule}

Rule digunakan sebagai dasar untuk teknik implikasi fuzzy. Rule memiliki dua bagian antara lain IF dan THEN. IF digunakan sebagai fakta dan THEN digunakan sebagai kesimpulan. Jika A adalah fakta dari variabel $\mathrm{x}, \mathrm{B}$ adalah kesimpulan dari variabel $\mathrm{y}$, dapat ditulis sebagai berikut (Hayadi, 2016):

$$
\text { IF } x \text { is } A \text { THEN B }
$$

Rule pada umumnya memiliki faktafakta lebih dari satu yang dihubungkan dengan operasi gabungan atau union $A N D$. Contoh dari Rule yang menggunakan lebih dari satu fakta adalah sebagai berikut:

IF a is X AND a is Y AND a is Z THEN B.

\section{Fuzzy Tsukamoto}

Fuzzy Tsukamoto Pada metode Fuzzy Tsukamoto, setiap konsekuen pada Rule yang berbentuk IF-Then harus direpresentasikan dengan suatu himpunan fuzzy dengan fungsi keanggotaan yang monoton sebagai hasilnya (proses fuzzifikasi). Keluaran hasil inferensi dari tiap-tiap Rule diberikan secara tegas (crisp) berdasarkan $\alpha$-predikat. Hasil akhirnya diperoleh dengan menggunakan defuzzifikasi rata-rata terbobot (Maryaningsih et al, 2013)..

Pada Metode Tsukamoto memiliki beberapa tahapan yaitu

1. Fuzzifikasi adalah proses untuk mengubah masukan sistem yang mempunyai nilai tegas atau crisp menjadi himpunan fuzzy dan menentukan derajat keanggotaannya di dalam himpunan fuzzy.

2. Inferensi Melakukan penalaran menggunakan fuzzy input dan fuzzy rules yang telah ditentukan sehingga menghasilkan fuzzy output.

3. Defuzzifikasi Mengubah fuzzy output menjadi nilai tegas berdasarkan fungsi keanggotaan yang telah ditentukan. Defuzzifikasi merupakan metode yang penting dalam pemodelan sistem fuzzy.

\section{METODE PENELITIAN}

Dalam penelitian ini metode yang digunakan yaitu dengan mengimplementasikan metode Fuzzy Tsukamoto. Penulis memperoleh data dengan cara mewawancarai pemilik usaha secara langsung, data yang diperoleh yaitu data persediaan dan data penjualan serta data produksi satu minggu terakhir. Berikut ini merupakan diagram alur metode penelitian yang dimulai dari identifikasi masalah, analisis kebutuhan, pengumpulan data, penentuan metode, implementasi dan pengujian metode serta kesimpulan. 


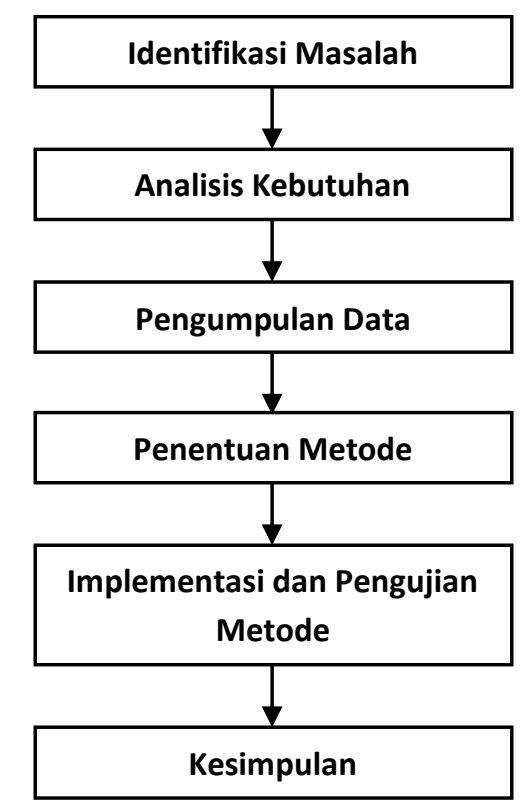

Gambar 1. Alur Penlitian

\section{HASIL DAN PEMBAHASAN}

Untuk menentukan Hasil prediksi dari jumlah produksi menggunakan metode tsukamoto maka di perlukannya sample data. kami mengambil data 1 minggu terakhir dari produksi TMG.

Tabel 1. Sample 1 Minggu

\begin{tabular}{cccc}
\hline Hari & Penjualan & Persediaan & Produksi \\
\hline Senin & 1845 & 55 & 1900 \\
Selasa & 1670 & 30 & 1700 \\
Rabu & 1955 & 45 & 2000 \\
Kamis & 1500 & 50 & 1550 \\
Jum'at & 2450 & 100 & 2550 \\
Sabtu & 3180 & 20 & 3200 \\
Minggu & 2970 & 30 & 3000 \\
\hline
\end{tabular}

Berdasarkan tabel diatas dengan menggunakan metode Tsukamoto Terdapat 3 variable fuzzy yang di dapatkan dari aturan Produksi

- Penjualan : Terdiri 2 himpunan fuzzy, yaitu turun $\&$ naik
- Persediaan : Terdiri 2 himpunan fuzzy, sedikit \& banyak

- Produksi: Terdiri 2 himpunan fuzzy, yaitu berkurang $\&$ bertambah

Table 2. Aturan Produksi Fuzzy Tsukamoto

\begin{tabular}{|c|c|}
\hline \multicolumn{2}{|r|}{$\begin{array}{c}\text { Proses Produksi Mata Gajah Memakai } 4 \\
\text { Aturan/rule Fuzzy }\end{array}$} \\
\hline \multirow{2}{*}{ R1 } & $\begin{array}{c}\text { IF (Jika) Sebuah Nilai Pejualan Turun } \\
\text { And Nilai Persediaan Banyak }\end{array}$ \\
\hline & $\begin{array}{c}\text { THEN (Maka) Nilai Produksi Roti } \\
\text { Berkurang }\end{array}$ \\
\hline \multirow{2}{*}{$\mathrm{R} 2$} & $\begin{array}{c}\text { IF (Jika) Sebuah Nilai Penjualan Turun } \\
\text { And Nilai Persediaan Sedikit }\end{array}$ \\
\hline & $\begin{array}{c}\text { THEN (Maka) Nilai Produksi Roti } \\
\text { Berkurang }\end{array}$ \\
\hline \multirow{2}{*}{ R3 } & $\begin{array}{c}\text { IF (Jika) Sebuah Nilai Penjualan Naik } \\
\text { And Nilai Persediaan Banyak }\end{array}$ \\
\hline & $\begin{array}{c}\text { THEN (Maka) Nilai Produksi Roti } \\
\text { Bertambah }\end{array}$ \\
\hline \multirow{2}{*}{ R4 } & $\begin{array}{l}\text { IF (Jika) Sebuah Nilai Penjualan Naik } \\
\text { And Nilai Persediaan Sedikit }\end{array}$ \\
\hline & $\begin{array}{c}\text { THEN (Maka) Nilai Produksi Roti } \\
\text { Bertambah }\end{array}$ \\
\hline
\end{tabular}

1. Penjualan

Terdiri dari 2 himpunan fuzzy, yaitu turun dan naik

Penjualan Terendah adalah 1500

Penjualan Tertinggi adalah 3180

Penjualan Permasalahan $=1845$

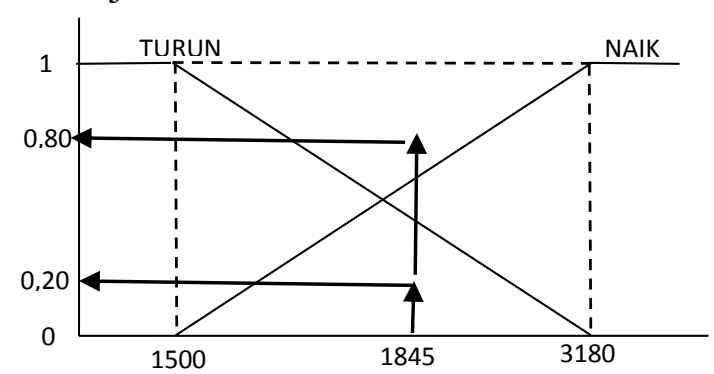


$\mu$ pejualan $-\operatorname{turun}[x]\left\{\begin{array}{cr}1 & x \leq 1500 \\ \frac{3180-x}{1680} . & x \geq 003180 \\ 0 & x \geq 3180\end{array}\right.$

$\mu$ pejualan - naik $[x]\left\{\begin{array}{cr}0 & x \leq 1500 \\ \frac{x-1500}{1680} & 1500 \leq x \leq 3180 \\ 1 & x \geq 3180\end{array}\right.$

\section{Persediaan}

Terdiri dari 2 himpunan fuzzy, yaitu SEDIKIT, dan BANYAK,

Persediaan terendah adalah 20

Persediaan tertinggi adalah 100

Persediaan permasalahan $=55$

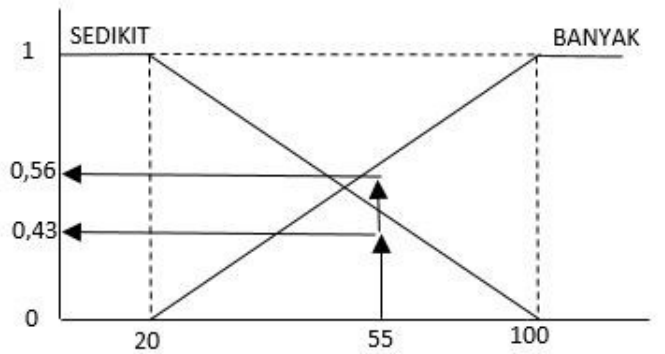

$\mu$ persediaan $-\operatorname{sedikit}[y]\left\{\begin{array}{cc}1 & x \leq 20 \\ \frac{100-y}{80} .20 \leq x \leq 100 \\ 0 & x \geq 100\end{array}\right.$

$\mu$ persediaan -banyak $[y]\left\{\begin{array}{cc}0 & x \leq 20 \\ \frac{y-20}{80} & 20 \leq x \leq 100 \\ 1 & x \geq 100\end{array}\right.$

3. Produksi

Terdiri dari 2 Himpunan Fuzzy, Yaitu BEKURANG dan BERTAMBAH

Produksi terendah adalah 1550

Produksi tertinggi adalah 3200

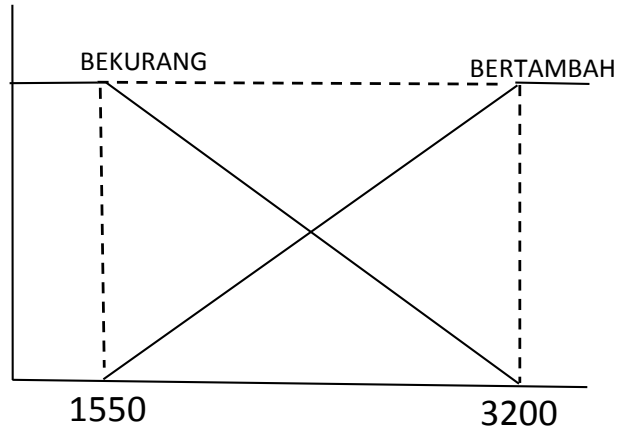

$\mu$ produksi - bekurang $[z]\left\{\begin{array}{cc}1 & z \leq 1550 \\ \frac{3200-z}{1650} & 1550 \leq z \leq 3200 \\ 0 & z \geq 3200\end{array}\right.$

$\mu$ produksi-bertambah $[z]\left\{\begin{array}{cr}0 & z \leq 1550 \\ \frac{z-1550}{1650} & 1550 \leq z \leq 3200 \\ 1 & z \geq 3200\end{array}\right.$

[R1] IF (Jika) Nilai Penjualan TURUN

And Nilai Persediaan BANYAK

THEN (Maka) Nilai Produksi TMG

Berkurang

Predikat 1

$=\mu$ penjualanTURUN $\cap \mu$ persediaanBANY

AK

$=\min (\mu$ penjualanTURUN $[1845], \mu$ persedia

anBANYAK[55])

$=\min (0,80 ; 0,56)$

$=0,80$

Himpunan Produksi TMG Berkurang $(3200-z) / 1650=0,80$

Hitung $Z 1=0,80 \times 1650=1320$

$3200-1320=1880$

Jadi $Z 1=1880$

[R2] IF (Jika) Nilai Penjualan TURUN

And Nilai Persediaan SEDIKIT

THEN (Maka) Nilai Produksi TMG

Berkurang

Predikat2

$=\mu$ penjualanTURUN $\cap \mu$ persediaanSEDIK IT

$=\min (\mu$ penjualanTURUN[1845], $\mu$ persedia

anSEDIKIT[55])

$=\min (0,80 ; 0,43)$

$=0,43$ 
Himpunan Produksi TMG Berkurang

$(3200-z) / 1650=0,43$

Hitung Z2 $=0,43 \times 1650=709.5$

$3200-709.5=2490,5$

Jadi $\mathrm{Z} 2=2490,5$

[R3] IF (Jika) Nilai Penjualan NAIK And Nilai Persediaan BANYAK

THEN (Maka) Nilai Produksi TMG

Bertambah

Predikat 3=

penjualanNAIK $\cap \mu$ persediaanBANYAK

$=\min (\mu$ penjualanNAIK[1845], $\mu$ persediaan

BANYAK[55])

$=\min (0,20: 0,56)$

$=0,20$

Himpunan Produksi TMG Bertambah (z $1550) / 1650=0,20$

Hitung Z3: $0,20 \times 1650=330$

$330+1550=1880$

$\mathrm{Z} 3=1880$

[R4] IF (Jika) Nilai Penjualan NAIK And

Nilai Persediaan SEDIKIT

THEN (Maka) Nilai Produksi TMG

Bertambah

Predikat 4=

$\mu$ penjualanNAIK $\cap \mu$ persediaanSEDIKIT

$=\min (\mu$ penjualanNAIK[1845], $\mu$ persediaan

SEDIKIT[55])

$=\min (0,20: 0,43)$

$=0,43$

Himpunan Produksi TMG Bertambah (z 1550) $/ 1650=0,43$

Hitung Z4 : 0,43 x $1650=709,5$

$709,5+1550=2259,5$

$\mathrm{Z} 4=2259,5$

a predikat $1 * Z 1+$ a predikat $2 * Z 2+$ a predikat $3 * Z 3+$ a predikat $4 * Z 4$ $=\frac{a \text { Predikat } 1+\text { a Predikat } 2+a \text { Predikat } 3+\text { a Predikat } 4}{4}$

$z=\frac{0,80 * 1880+0,43 * 2490,5+0,20 * 1880+0,43 * 2490,5}{0,80+0,43+0,20+0,43}$

$$
z=\frac{4021,83}{1.86}
$$

$Z=2,162$

\section{KESIMPULAN}

Berdasarkan penelitian yang telah dilakukan dapat disimpulkan bahwa metode fuzzy tsukamoto dapat di implementasikan untuk membantu memprediksi jumlah produksi Telor mata gajah, Hasil yang diperoleh dengan menggunakan metode fuzzy Tsukamoto untuk memprediksi produksi Mata Gajah Amrozy yakni memperoleh hasil 2162 TMG yang harus diproduksi. Sehingga hasil penelitian ini bisa menjadi pertimbangan untuk menentukan jumlah rata-rata dalam memproduksi TMG kedepannya.

\section{DAFTAR PUSTAKA}

A. Prayogi, E. Santoso, and Sutrisno, Sistem Pendukung Keputusan Untuk Penentuan Jumlah Produksi Nanas Menggunakan Metode Fuzzy Tsukamoto (Studi kasus PT.Great Giant Pineapple) - J. Pengemb. Teknol. Inf. dan Ilmu Komput., vol. 2, no. 6, p. 6, 2018.

Hidayat Nurul, Suwandi Galih Putra, Sistem Diagnosis Penyakit Mata Menggunakan Metode Fuzzy Tsukamoto. Jurnal Pengembangan Teknologi Informasi dan Ilmu Komputer - Vol. 3, No. 4, April 2019, ISSN: 3531-3537 (Print) 2548-964X (Online)

K. I. Fathurrahman, Penerapan Fuzzy Tsukamoto Dalam Sistem Pendukung Keputusan Untuk Menentukan Jumlah Produksi Barang. Lembaga Pengembangan Pembelajaran, Penelitian \& Pengabdian Kepada Masyarakat, 2014.

Marbun. Murni, T. S. Hengki, V. M. Normi, "Perancangan Sistem Perencanaan Jumlah Produksi Roti Menggunakan Metode Fuzzy Mamdani, Jurnal Mantik Penusa Volume 20, No.1, Desember 2016. 
Maryaningsih, Siswanto \& Mesterjon, Metode Logika Fuzzy Tsukamoto Dalam Sistem Pengambilan Keputusan Penerimaan Beasiswa. JurnalMedia Infotama, 9(1 februari 2013), pp. 1-13. 2013.

L. R. Dorteus, Penerapan Logika Fuzzy Metode Sugeno Untuk Menentukan Jumlah Produksi Roti Berdasarkan Data Persediaan Dan Jumlah Permintaan (Studi Kasus: Pabrik Roti Sarinda Ambon), Jurnal Ilmu Matematika dan Terapan. 2015.

Sutojo \& dkk, (2011). Kecerdasan Buatan. Yogyakarta: Andi.

W. Kaswidjanti, Implementasi Fuzzy Inference System Metode Tsukamoto pada Pengambilan Keputusan Pemeberian Kredit Pemilikan Rumah, Telematika - vol.10, 2014. 